\title{
A MEASURE OF LIQUIDITY RISK IN A SOVEREIGN DEBT MARKET
}

\author{
Emma Berenguer (*) \\ Universidad Pablo de Olavide \\ Ricardo Gimeno \\ Banco de España \\ Juan M. Nave \\ Universidad Castilla la Mancha
}

VERY PRELIMINAR, DO NOT QUOTE

\begin{abstract}
Since the seminal paper of Vasicek and Fong (1982) term structure models are estimated assuming that yields are cross-sectionally homokedastic. In this paper, we show that this hypothesis does not hold even for bonds from the same issuer when there are differences in their level of liquidity. Those bonds with a lower daily turnover would experiment a higher volatility around the expected yield determined by the term structure. The existence of a minimum tick size on the bond price negotiation would also produce a higher volatility for those bonds approaching their expiration term. In order to show these effects, we use data from Spanish sovereign bonds from 1988 to 2010, covering more than 700 bonds and 5000 days. With these data we have estimated the out-of-sample error for each bond and day. The variance of these errors is negatively correlated with the turnover of each bond and its duration, while the mean of the error is directly correlated with the estimated variance. Taking into account these features we propose, for fitting the term structure, a modified Svensson (1994) yield curve model where an additional liquidity term is added and parameters are estimated by weighted least squared errors to take into account the liquidity-induced heterokedasticity.
\end{abstract}

Keywords: liquidity risk; liquidity premium; yield curve; Spanish Sovereign Bonds

JEL classification: G12; C58; E43.

(*) Corresponding Author:

Emma Berenguer Cárceles. email: ebercar@upo.es

The authors acknowledge financial support from the Ministry of Science and Innovation (grant ECO2009-13616/ECON) 


\section{INTRODUCTION}

In the financial literature, there is little disagreement that liquidity is the second most important factor after credit risk that affects the yields of bonds. However, it is one of the least understood areas of finance. Since the pioneer work of Fisher (1959) pointed out that it was liquidity the variable responsible for the existing differentials of profitability between the titles of private equity and the titles of Government Securities (GS), many authors have studied the liquidity factors on the debt markets.

Some studies make inferences about bond liquidity or about the valuation implications of liquidity differences using such proxies for liquidity as securities age (Sarig and Warga, 1989), security type (Amihud and Mendelson, 1991; Kamara, 1994), ontherun/offtherun status (Warga, 1992), trading volume (Elton and Green, 1998) and term to maturity (Shen and Starr, 1998). The case for a liquidity premium ${ }^{1}$ has been more frequently treated in the literature (i.e. Amihud and Mendelson, 1986; Elton and Greene, 1998; Alonso et al., 2004; Diaz et al., 2006).

The main goal of this paper is to present a model able to explaining the role played by liquidity considerations in the departure of sovereign bond yields from a theoretical liquidity-free term structure of interest rates.

In the recent financial crisis, where spreads between Sovereign bonds issued by different countries has been used as a measure of credit risk differences, preferences for more liquid bonds ${ }^{2}$ may have been distorting the supposed meaning of these spreads, imposing an upward bias. Liquidity considerations may have also implied an undesired role in the interpretation of the differences between nominal bonds and inflation-linked bonds as inflation compensation, since liquidity differences in favour of nominal bonds produce a downward bias in the supposed market inflation expectations. Therefore, liquidity spreads have received increasing attention in the literature. Nevertheless, the effect of liquidity factors on yield variance has received less attention.

\footnotetext{
${ }^{1}$ Amihud and Mendelson (1986) stated that the first consequence of the liquidity factor is the major or minor exigency of a return. These differences are known as liquidity premiums and are deviations from the yields of the different assets to compensate differences in liquidity.

2 Bond spreads increase during recessions due to a phenomenon called flight-to-liquidity and flight-toquality (Goyenko et al., 2011).
} 
Lately, the Eurobonds ${ }^{3}$ have been the object of intense political debate due to the threat of Greece's default. The argument in favour of these assets goes in the line of the liquidity improvement over individual sovereign bonds, which could reduce the cost of issuance.

Alonso et al. (2004) define liquidity as the ease of its conversion into money whereas Díaz et. al (2006) defines liquidity as a feature of financial assets related to the ease with which a security can be traded within a short period of time period of time without causing significant impact on prices. The main consequence of the lack of liquidity is that in the case of a trader willing to either buy or sell a given asset, the direction of the trade will have a sizeable effect on the price, been this movement upward in the case of a buy order or downward for a sell order. Therefore, price changes will be higher for illiquid assets, which imply differences in the associated variance of the bonds due to their different degree of liquidity.

In the case of fixed rate securities, differences in the level of liquidity would cause wider movements for less liquid bonds, both in the upside and in the downside. Therefore, liquidity considerations should imply differences in their associated variance, even for those bonds from the same issuer. Main direct implication of this heterokedasticity will appear for the estimation of the yield curve. Since the paper of Vasicek and Fong (1982), term structures of interest rates are estimated assuming that yields are homokedastic, and this assumption has been applied since then in the subsequent models proposed in the literature (i.e. Nelson and Siegel, 1987; Svensson, 1994; Bliss, 1997; Jordan and Mansi, 2003). A vast majority of Central Banks use this error correction in their model estimation. In fact, the Bank of International Settlements (2005) shows that 6 out of 11 Central Banks use the weighted prices to estimate the term structure. Nevertheless, the evidence presented in this paper show that this Vasicek and Fong (1982) assumption of homokedastic yield errors no longer holds when the bonds considered have different levels of liquidity.

\footnotetext{
${ }^{3}$ Defined as "pooled" sovereign debt instruments of the member States of the euro area.
} 
The problem behind the approach above stem from the way liquidity is considered. For GS, Alonso et al. (2004) stated that liquidity should be closely linked to the marketmakers' inventory risk and order-processing costs which ultimately depend on the level of risk of the asset (duration) and the frequency with which a transaction will be executed (turnover). The on-the-run issues are those more recently auctioned and tend to be more liquid than previous issued bonds (off-the-run) maturing on similar dates (Pasquariello and Vega, 2009). Nevertheless, even among these bonds there might be differences on liquidity, and therefore, heteroskedasticity among the yields.

By contrast, Amihud and Mendelson (1991) proposed a model for short term interest rates where yields had a variance that was conditional on the time to maturity. Although this approach deal with the duration component of liquidity does nothing with the trading volume factor. In this sense, Elton and Greene (1998) proposed a model for the term structure estimated minimizing the mean root squared error, but the errors are then used in a liquidity model where the parameters are estimated using a heteroskedasticity and autocorrelation consistent estimate of the variance (HAC estimator). Díaz et al. (2011) considered the heteroskedasticity of the interest rates but used a time series approach rather than a cross-sectional liquidity related approach.

Elton and Greene (1998) propose the trading volume as the main variable producing liquidity differences among bonds with the same issuers. However, as this variable is not always available, some authors use proxies of this variable. The most common one is the classification of the bonds in on-the-run (the most recently auctioned issue), offthe-run (next to the most recently auctioned issue) and off-off-the-run (older issued bonds). That is the case for Alonso et al. (2004) and Diaz et al. (2006). Both Alonso et al. (2004) and Diaz et al. (2006) also include the pre-benchmark category that includes the first days of a new issue, where there is not enough trading volume on that issue yet.

Alonso et al. (2004) verify the existence of liquidity premiums in the prices of titles negotiated in the Spanish GS market. The methodology used is that of Elton and Green (1998), based on the estimation of the Term Structure of Interest Rates. These authors incorporate the effect of the liquidity in the estimation introducing dummy variables for the different categories (on-the-run/off-the-run) of the bonds. The instantaneous forward remains defined according to the method of Svensson (1994). 
Díaz et al. (2006) analyse the liquidity structure of the Spanish Treasury bond market using trading volume market share and "auction status" as proxies for liquidity to determine if the entry of Spain in the European Monetary Union (EMU) has had some repercussion in liquidity. They also analyse the impacts of EMU on volatility of yields in the Spanish treasury market ${ }^{4}$, finding a dramatically decline after the market began pricing EMU.

In this paper we propose a heterokedastic model for the yields, where the variance equation is function of the trading volume and the duration, allowing for consistent estimators of the yield curve in the sense of White (1980).

Following both Elton and Greene (1998) and Alonso et al. (2004), we add a term of liquidity on the estimation of the Svensson (1994) term structure model. But we depart from both papers in the sense that we use the heteroskedasticity variable estimated for the variance equation for the term structure, instead of the trading volume like Elton and Greene (1998) or the on-the-run/off-the-run quality of the bonds like Alonso et al. 2004). In this way, we use a model that assimilates to a garch-in-mean model.

The rest of the paper is organized as follows. The next section describes the data. On Section 3 we show that liquidity factors produce heteroskedasticity in the GS yields. On Section 4 we modified Svensson (1994) model in order to incorporate liquidity constrains when estimating the term structure, both in the mean and the variance equation. On Section 5 we estimate the model with the Spanish sovereign bonds, and on section 6 we give some conclusion.

\section{Data}

The database used for the following sections is provided by Banco de España public webpage and contains all transactions in the secondary market called Spanish Public Debt Market. This database has been previously used by Díaz et al. (2006). This titles are classified, depending on their maturities in Letras del Tesoro (equivalent to US Treasury Bills, short-term zero-coupon bonds, with maturities up to eighteen months),

\footnotetext{
${ }^{4}$ Díaz et al. (2006) use Nelson \& Siegel (1987) exponential model to fit the daily term structures. They do not incorporate any specific liquidity effects.
} 
Bonos del Estado (equivalents to US Treasury notes with maturities ranging from 3 to 5 years that earn a fixed rate of interest every year until maturity) and Obligaciones del Estado (similar to Bonos but with larger maturities of 10, 15 and 30 years). Their nominal value is of 1.000 Euros. Despite their different denominations we will refer to all of them hereafter as Bonds.

As explained by Diaz et al. (2006), this database reports daily information on the number of transactions and both the nominal and effective volumes for each issue, as well as the maximum, minimum and the average price for each day. The database provides data for a period that goes from 1988 until 2010, and supposes a total of almost 5.000 trading days, and 700 issues and a total of 121.758 observations. For each working day of the period the prices are taken from the daily series provided by the Bank of Spain (and available on its web) ${ }^{5}$.

To estimate the short term we have taken the notes (Letras del Tesoro). For the long term we cannot find assets issued at discount (which make the estimation easier), so we have to use bonds (Bonos del Estado and Obligaciones del Estado). From 1997 segregation of the notes and obligations of public debt is permitted, turning them into titles coupon zero called strips. Nevertheless, these assets were not very successful and were not having the enough volume of negotiation required. De Andrés et al. (2004) have studied the volume of negotiation of these titles trough the period 1998-2003. They found that transactions with strips had represented in 1998 not more than 2 for 100 of the total of operations with Public Debt in average and only the 0.5 for 100 of the same total in 2003. This lack of liquidity on the market of strips cause distortions in the prices that will concern the form of the zero coupon curve in case of being used in the estimation.

From this data, we have produced daily estimations of the yield curve using Svensson (1994) model implementing the algorithm proposed by Gimeno and Nave (2009). This model modifies the original work of Nelson and Siegel (1987). To do so, uses a second term (the one that Nelson and Siegel (1987) had abandoned in their work) and added another constant parameter $\varphi_{6}$. The equation for the instantaneous forward rate is:

5 Since 1988 the Bank of Spain has been building a database from closing prices. http://www.bde.es/webbde/es/secciones/informes/banota/series.html 
$f(t)=\varphi_{1}+\varphi_{2} \cdot e^{-\frac{t}{\varphi_{5}}}+\varphi_{3} \cdot \frac{t}{\varphi_{5}} e^{-\frac{t}{\varphi_{5}}}+\varphi_{4} \cdot \frac{t}{\varphi_{6}} e^{-\frac{t}{\varphi_{6}}}$

Equation (1) generates a complete family of forward curves that reflects all Term Structure possible shapes.

Integrating equation (1) between $[0, t]$ and dividing into $t$ results a equation that relates spot interest rate to time to maturity:

$s(t)=\varphi_{1}+\varphi_{2} \frac{1-e^{-t / \varphi_{5}}}{\left(t / \varphi_{5}\right)}+\varphi_{3}\left[\frac{1-e^{-t / \varphi_{5}}}{\left(t / \varphi_{5}\right)}-e^{-t / \varphi_{5}}\right]+\varphi_{4}\left[\frac{1-e^{-t / \varphi_{6}}}{\left(t / \varphi_{6}\right)}-e^{-t / \varphi_{6}}\right]$

And replacing the discount function, the equation remains:

$v(t)=\exp \left[-\varphi_{1} t-\left(\varphi_{2}+\varphi_{3}\right) \varphi_{5}\left(1-\exp \left(-\frac{t}{\varphi_{5}}\right)\right)+\varphi_{3} t \exp \left(-\frac{t}{\varphi_{5}}\right)-t \varphi_{4}\left(\frac{\varphi_{6}}{t}\left(1-\exp \left(-t / \varphi_{6}\right)\right)-\exp \left(\frac{-t}{\varphi_{6}}\right)\right)\right]$

where $t$ is the term and $\varphi_{1}, \varphi_{2}, \varphi_{3}, \varphi_{4,}, \varphi_{5} \mathrm{y} \varphi_{6}$ the parameters to be estimated. Svensson (1994) originally estimates by maximum likelihood.

The choice of this method is based on both its presence in a considerable number of studies, due to the great number of Central Banks that use it $^{6}$ (including the Bank of Spain); and the best performance the model has shown in the Spanish Government Debt Market, compared to other parametric models ${ }^{7}$.

Following Bliss (1996) we computed errors out-of-the-sample, the daily estimations are as many as the number of titles in that day. On each estimation, we leave out of the

\footnotetext{
${ }^{6}$ See Bank of International Settlements (2005).

${ }^{7}$ See Núñez (1995) and Berenguer (2009).
} 
sample one title each time. This methodology will allow us to compute the yield deviations (as difference between observed yield and estimated) with the titles not included in the sample.

\section{A liquidity model}

The purpose of this model is to explain the value of the liquidity deviation from the model implied interest rates $\left(l_{i t}\right)$. In this approach, we proxy the liquidity error as the difference between the quoted yield of a bond $(i)$ and its yield implied by the out-ofsample Svensson term structure model for a given day $(t)$. In the presence of liquidity considerations, these errors should be strongly influenced by two factors:

- Turnover or trading volume $\left(T_{i t}\right)$. If the bond is rarely traded, matching operation would be difficult to reach, and the willing seller (buyer) would have to accept a lower (higher) price in order to complete the order. Elton and Green (1998) signaled that trading volume was a more robust measure of asset liquidity than other proxies used in other studies such as type of security. For instance, Warga (1992) and Alonso et al. (2004), among others, proxied trading volume by the on-the-run/off-the-run classification.

- Tick size. Bond pricing implies that the same price changes has a different effect on a bond depending on their time to maturity $\left(d_{i t}\right)$, so those close to maturity will experience higher return swings than the rest. Amihud and Mendelson (1991) found evidence that there was a liquidity premia that was decreasing and convex function of the time to maturity.

Liquidity constrains would produce wider movements for less liquid bonds, both in the upside and in the downside. Therefore, liquidity considerations should imply differences in the variance of $l_{i t}$ (heterokedasticity). In these sense, Amihud and Mendelson (1991) proposed a model where yields had a variance that was conditional on the time to maturity. The unobserved variance variable $\left(h_{i t}\right)$ would depend, both on turnover (there would be a negative relationship between turnover and variance) and on time of maturity (there would be a positive relationship between the inverse of the 
duration and the variance). Therefore, a heterokedastic model for the yield errors $\left(l_{i t}\right)$ would be equal to the one in equation [4].

$$
l_{i t}=\beta_{0}+\sqrt{h_{i t}} \cdot \varepsilon_{i t} \quad \varepsilon_{i t} \sim N[0,1]
$$

$\log h_{i t}=\gamma_{0}+\gamma_{1} \cdot \log T_{i t}+\gamma_{2} \cdot \frac{1}{D_{i t}}$

In the variance equation, we would expect that $\gamma_{1}<0$ and $\gamma_{2}>0$, if both turnover and the tick size explain the variance of $l_{i t}$. In Table 1 , model 1 represents the estimations of parameters of equation [4]. As can be seen, both turnover and duration coefficients have the expected sign (negative for the turnover and positive for the duration). This result confirms that yields are not homokedastic, a feature that we will use in the models of next section.

Although these variables affect primarily the variance of $l_{i t}\left(h_{i t}\right)$, this is far to be the only expected effect. A difference in the variance of the yields of different bonds implies a different level of risk for an investor. Therefore, we would expect that investors would ask for higher return in the case of bonds that are susceptible of higher liquidity volatilities. Thus, the level of the variance $\left(h_{i t}\right)$ would also affect the level of the yield (the level equation).

$$
\begin{array}{ll}
l_{i t}=\beta_{0}+\beta_{1} \cdot \log h_{i t}+\sqrt{h_{i t}} \cdot \varepsilon_{i t} & \varepsilon_{i t} \sim N[0,1] \\
\log h_{i t}=\gamma_{0}+\gamma_{1} \cdot \log T_{i t}+\gamma_{2} \cdot \frac{1}{D_{i t}} &
\end{array}
$$

The variance equation remains invariant with respect specification of equation [4], where we expected that $\gamma_{1}<0$ and $\gamma_{2}>0$, if both turnover and the tick size explain the range of movements in $l_{i t}$. Nevertheless, in the level equation, the heterokedastic behavior of $l_{i t}$ would be derived from the first term $\left(h_{i t}{ }^{2} \varepsilon_{i t}\right)$, while these differences in volatility would be compensated by a higher liquidity premium $\left(\beta_{1} \cdot \log h_{i t}\right)$. Therefore, 
parameter $\beta_{1}$ will be the price of liquidity risk. We would expect that $\beta_{1}>0$, implying that investors demand a premia for the risk they are assuming ${ }^{8}$.

In model 2 in table 1, we present the parameters estimations of model [5]. As can be seen, parameters estimated in the variance equation are similar to the ones we obtained in model 1, and both turnover and duration coefficients have the expected sign (negative for the turnover and positive for the duration). The main difference is in the case of the level equation, where we also find the expected positive price of risk

\section{Svensson model modified to take liquidity into account}

Vasicek and Fong (1982) estimated the term structure of interest rates assuming that bond returns were homokedastic. Nevertheless, nonlinear optimization methods are extremely simplified if we define error in terms of prices instead of yields. In these circumstances, the price of a bond, given a certain term structure defined by function $s(t, \varphi)$ is computed as:

$$
\hat{P}=\sum_{j=1}^{n} C_{j} \cdot e^{-s\left(t_{j}, \varphi\right) \cdot t_{j}}+N \cdot e^{-s(m, \varphi) \cdot m}
$$

Where $C_{j}$ are the $n$ periodical coupons payables at times $t_{1}, t_{\mathrm{z}}, \ldots, t_{m}, N$ is the nominal of the bond, $m$ is the maturity of the bond and $s(t, \phi)$ is the spot interest rate derived from the Svensson (1994) term structure model:

$$
s(t, \varphi)=\varphi_{1}+\left(\varphi_{2}+\varphi_{3}\right) \cdot\left(\frac{\varphi_{5}}{t}\right) \cdot\left(1-e^{\frac{-t}{\varphi_{5}}}\right)-\varphi_{3} \cdot e^{\frac{-t}{\varphi_{5}}}+\varphi_{4} \cdot\left(\frac{\varphi_{6}}{t}\right) \cdot\left(1-e^{\frac{-t}{\varphi_{6}}}\right)-\varphi_{4} \cdot e^{\frac{-t}{\varphi_{6}}}
$$

Vasicek and Fong (1982) showed that if yield errors are homokedastic (Variance equal to $\sigma^{2}$ ), then the variance of the price error would be proportional to the squared of the sensibility of the bond price to variations in the yield (the duration):

$E\left[(P-\hat{P})^{2}\right]=\sigma^{2} \cdot\left(\frac{d P}{d s}\right)^{2}$

\footnotetext{
${ }^{8}$ Although it is reasonable to suppose that the price of risk change in time (increasing with the crisis and decreasing in normal times) for simplicity we have suppose in this section that the price of risk is constant. In next section, we present a model where the price of risk is estimated in a daily base.
} 
Therefore, if we want to recover the yield curve, we would need to weight the price squared errors by the inverse of the duration in order to obtain an objective function.

$$
\hat{\varphi}=\min _{\varphi} \sum_{i=1}^{k}\left(P_{i}-\hat{P}_{i}(\varphi)\right)^{2} \cdot \frac{1}{D_{i}}
$$

Nevertheless, in previous section we have shown that Vasicek and Fong (1982) assumption of homokedastic yield errors no longer holds when the bonds considered have different levels of liquidity. Therefore, the usual weighting aggravates the observed heterokedasticity instead of correcting it. In fact, the variance for the price error would be,

$$
E\left[(P-\hat{P})^{2}\right]=h_{i} \cdot\left(\frac{d P}{d s}\right)^{2}
$$

Where $h_{i}$ is the heterokedastic model we proposed in previous section:

$$
\log h_{i t}=\gamma_{0}+\gamma_{1} \cdot \log T_{i t}+\gamma_{2} \cdot \frac{1}{D_{i t}}
$$

And the estimation of the term structure will require the jointly estimation of the parameters of both the term structure (equation [7]) and the variance equation (equation [11]):

$$
(\hat{\varphi}, \hat{\gamma})=\min _{\varphi, \gamma} \cdot \sum_{i=1}^{k}\left(P_{i}-\hat{P}_{i}(\varphi)\right)^{2} \cdot \frac{1}{D_{i} \sqrt{h_{i}}}
$$

\section{Liquidity premia}

Previous model does not take into account the presence of a liquidity premia. It just considers the variability in prices derived from these liquidity considerations. In order to include this in the model we should vary equation [6] to add an additional term:

$\hat{P}=\sum_{j=1}^{n} C_{j} \cdot e^{-s\left(t_{j}, \varphi\right) \cdot t_{j}-\alpha \cdot h}+N \cdot e^{-s(m, \varphi) \cdot m-\alpha \cdot h}$ 
This would be equivalent to multiply the estimated price by $e^{-\boldsymbol{x} \cdot h}$ or to add $\alpha h / t$ to the bond yield. By contrast, equation [11] and [12] would remain valid. This model is similar to the one proposed by Elton and Greene (1998), where the log of the trading volume was added for the pricing equation.

\section{Model estimation}

In table 3a-3c we present term structure model estimations in three different days: April $20^{\text {th }}, 2010$ (in the way to the first Euro Area Sovereign Debt Crisis), May $11^{\text {th }}, 2010$ (Just in the middle of the Greek sovereign debt first crisis), and July $7^{\text {th }}, 2010$ (in the middle of the market easing after the publishing of European banks' stress tests). For each day, we compute four different estimations:

1. A traditional Svensson model (Equation [7]), minimizing equation [9], that is weighting error prices by the modified bond duration.

2. A Svensson model (Equation [7]), but using as minimizing program equation [12]. In order to get the $\widehat{h}_{i t}$ we need to compute the weights, we approach it by the squared differences between observed and estimated yields $(y)$ from previous model. Once we have those estimated errors, we estimate a regression similar to the one we would use in a White heterokedasticity test (equation [14]) and use the modeled variance to minimize equation [12].

$$
\log \left(y_{i t}-\hat{y}_{i t}\right)^{2}=\gamma_{0}+\gamma_{1} \cdot \log T_{i t}+\gamma_{2} \cdot \frac{1}{D_{i t}}
$$

3. A joint mean (Svensson equation [7]) and variance (equation [11]) estimation. In this case, we do not need to rely on the traditional duration-weighted estimators to obtain the variance equation.

4. Model [13], where we include a compensation for liquidity risk $(\boldsymbol{\alpha})$ in the price equation as well as a variance equation (Equation [11]) jointly estimated. 
As can be seen in the attached tables, the liquidity premia was higher in the middle of the Greek debt crisis (May 11 ${ }^{\text {th }}, 2010$ ) than before, or after those days.

\section{Conclusions}

In this paper we have tried to explain the role played by liquidity on the deviations of sovereign bonds yields from a theoretical liquidity-free term structure of interest rates. In this process, we observed that differences in the level of liquidity of the titles would cause wider movements of prices for less liquid bonds, therefore liquidity considerations should imply differences in their associated variance.

In this sense, we propose a heterokedastic model for the yields of the bonds, where the variance equation is function of the trading volume and the duration. After estimation of this model we obtained the expected sign of the coefficients (negative for the turnover and positive for the duration). This seems to confirm that liquidity differences among bonds from the same issuer can produce heterokedasticity.

Main direct implication of this heterokedasticity appears for the estimation of the yield curve. Vasicek and Fong (1982) estimated the term structure of interest rates assuming that bonds returns were homokedastic, and they proposed an error correction that consisted in weighting the price squared errors by the inverse of the duration. In this paper we have showed that this hypothesis does not hold, even for bonds from the same issuer, when there are differences in their level of liquidity. Therefore, cross-sectional models for the term structure should be corrected for liquidity differences.

Finally, to take into account the presence of a liquidity premia, we propose a Svensson model modified by liquidity risk similar to the one proposed by Elton and Green (1998). 


\section{References}

Alonso, F., Blanco, R., Río, A.D. and Sanchís, A., 2004. "Estimating Liquidity Premia in the Spanish Government Securities Market". The European Journal of Finance, vol. 10, no. 6, pp. 453-474.

Amihud, Y. and Mendelson, H., 1986. "Asset Pricing and the Bid-Ask Spread". Journal of Financial Economics, vol. 17, no. 2, pp. 223-249.

Amihud, Y. and Mendelson, H., 1991. "Liquidity, Maturity, and the Yields on US Treasury Securities". The Journal of Finance, vol. 46, no. 4, pp. 1411-1425.

Bank for International Settlements, 2005. Zero Coupon Yield Curves: Technical Documentation.

Bliss, R.R., 1997. "Testing Term Structure Estimation Methods". Advances in Futures and Options Research, vol. 9, pp. 197-232.

De Andrés, J., Molina, M. and Sardà, S., 2004. "El Mercado De Strips Sobre Deuda De Estado Española Durante El Período 1998-2003. Volúmenes y Rendimientos". Boletín De Información Comercial Española, pp. 15-25.

Díaz, A, Merrick, J.J and Navarro, E., 2006. "Spanish Treasury bond market liquidity and volatility pre- and post-European Monetary Union". Journal of Banking y Finance. Vol.30. 1309-1332

Díaz, A, Jareño, F and Navarro, E., 2011. "Term structure of volatilities and yield curve estimation methodology". Quantitative Finance, 11: 4, 573-586.

Elton, E.J. and Greene, T.C., 1998. "Tax and Liquidity Effects in Pricing Government Bonds". The Journal of Finance, vol. 53, no. 5, pp. 1533-1562.

Fisher, L., 1959. "Determinants of Risk Premiums on Corporate Bonds". The Journal of Political Economy, vol. 67, no. 3, pp. 217-237.

Gimeno, R. and Nave, J.M., 2009. "A Genetic Algorithm Estimation of the Term Structure of Interest Rates". Computational Statistics \& Data Analysis, vol. 53, no. 6, pp. 2236-2250.

Goyenko, R., Subrahmanyam, A. and Ukhov, A., 2011. "The Term Structure of Bond Market Liquidity and Its Implications for Expected Bond Returns". Journal of Financial and Quantitative Analysis, vol. 46, pp. 111-139.

Jordan, J. and S. Mansi, 2003. "Term structure estimation from on-the-run Treasuries,". Journal of Banking and Finance, vol. 27, pp. 1487-1509.

Kamara, A., 1994. "Liquidity, Taxes, and Short-Term Treasury Yields". Journal of Financial and Quantitative Analysis, vol. 29, no. 03, pp. 403-417. 
Nelson, C.R. and Siegel, A.F., 1987. "Parsimonious Modeling of Yield Curves". The Journal of Business, vol. 60, no. 4, pp. 473-489.

Pasquariello, P. and Vega, C., 2009. "The on-the-run liquidity phenomenon," Journal of Financial Economics, vol. 92(1), pp. 1-24.

Sarig, O. and A. Warga, 1989. "Bond Price Data and Bond Market Liquidity", Journal of Financial and Quantitative Analysis, vol. 24, pp. 367-378.

Shen, P. and Starr, R.M., 1998. "Liquidity of the Treasury Bill Market and the Term Structure of Interest Rates". Journal of Economics and Business, vol. 50, no. 5, pp. 401417.

Svensson, L.E.O., 1994. "Estimating and Interpreting Forward Interest Rates: Sweden 1992-1994". IMF Working Paper No. WP/94/114.

Vasicek, O.A. and Fong, H.G., 1982. Term Structure Modeling using Exponential Splines. The Journal of Finance, vol. 37, no. 2, pp. 339-348.

Warga, A., 1992. "Bond Returns, Liquidity, and Missing Data". Journal of Financial and Quantitative Analysis, vol. 27, no. 04, pp. 605-617.

White, H., 1980. "A heteroskedasticity-consistent covariance matrix estimator and a direct test for heteroskedasticity", Econometrica, vol. 48, pp. 817-838. 
TABLE 1: Heterokedastic models for the out of sample yield errors.

\begin{tabular}{|lcc|}
\hline & Model 1 & Model 2 \\
Level Equation & - & \\
Intercept & 0,989 & -0.240 \\
$\log \left(h_{i t}\right)$ & & $0.184 * * *$ \\
Variance & & \\
Equation & & \\
Intercept & 3,373 & 3.290 \\
$\log \left(\right.$ Turnover $\left._{i t}\right)$ & $0,133 * * *$ & $-0.129 * * *$ \\
$1 /$ Duration $_{i t}$ & $0,139 * * *$ & $0.142 * * *$ \\
\# of observations & & 121758 \\
\# of days & & 4996 \\
\# of bonds & & 662 \\
\hline
\end{tabular}

Individual LR tests have been computed for each parameter (outside the intercepts) under the null hypothesis of non significant variable. ${ }^{* * *}$ denotes rejection of the null at a $1 \%$ level, $* *$ at $5 \%$ and $*$ at $10 \%$. 
TABLE 2: Heterokedastic models for the out of sample yield errors for bonds with different maturities.

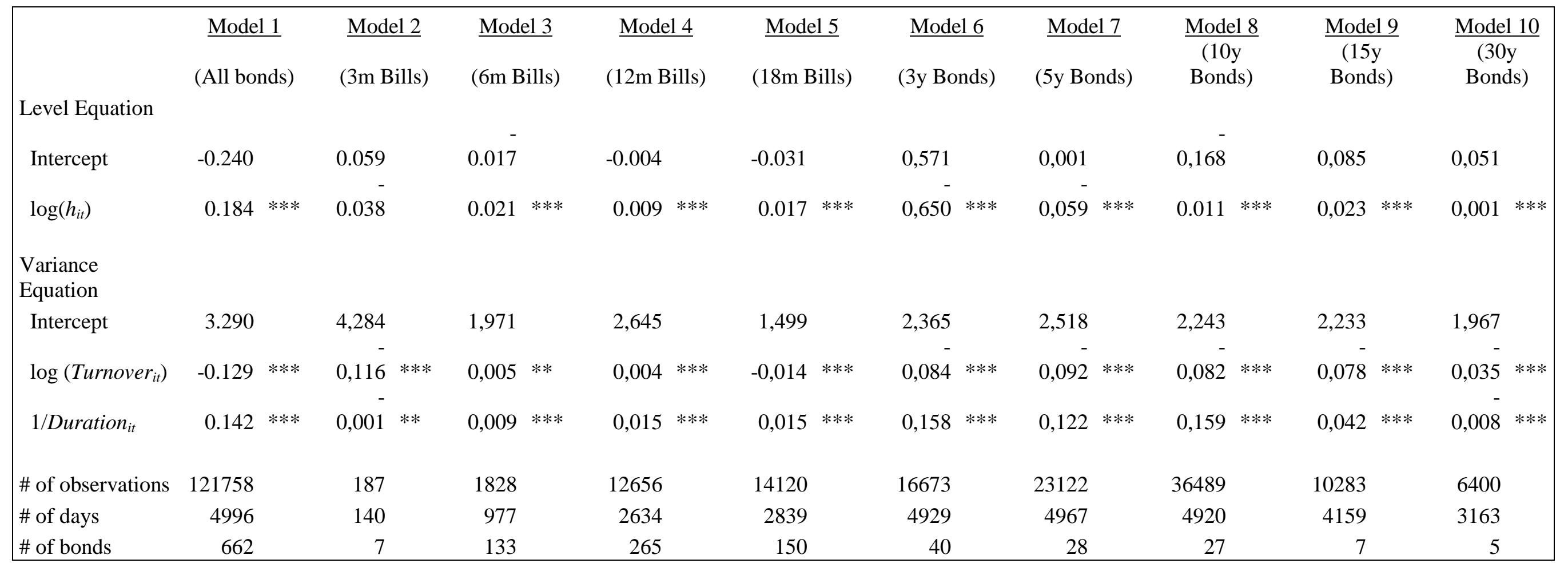

Individual LR tests have been computed for each parameter (outside the intercepts) under the null hypothesis of non significant variable. $* * *$ denotes rejection of the null at a $1 \%$ level, $* *$ at $5 \%$ and $*$ at $10 \%$. 
TABLE $3 a$.

\begin{tabular}{|c|c|c|c|c|}
\hline \multicolumn{5}{|c|}{$20 / 04 / 2010$} \\
\hline & $\begin{array}{l}\text { Duration- } \\
\text { Weighted }\end{array}$ & $\begin{array}{l}\text { Liquidity- } \\
\text { Weighted }\end{array}$ & $\begin{array}{l}\text { Mean-Variance } \\
\text { Joint Estimation }\end{array}$ & $\begin{array}{c}\text { Liquidity } \\
\text { Premia Model }\end{array}$ \\
\hline$\gamma_{0}$ & - & -12.412 & 9.344 & 10.869 \\
\hline$\gamma_{1}$ & - & -0.237 & -0.248 & -0.313 \\
\hline$\gamma_{2}$ & - & 0.572 & 1.177 & 1.179 \\
\hline$\alpha$ & - & - & - & 0.000121 \\
\hline$\varphi_{1}$ & 0.022 & 0.022 & 0.024 & 0.023 \\
\hline$\varphi_{2}$ & -0.019 & 0.000 & 0.000 & 0.000 \\
\hline$\varphi_{3}$ & 0.041 & 0.039 & 0.028 & 0.031 \\
\hline$\varphi_{4}$ & 0.085 & 0.086 & 0.087 & 0.092 \\
\hline$\varphi_{5}$ & 5.575 & 5.238 & 4.059 & 4.142 \\
\hline$\varphi_{6}$ & 20.945 & 17.900 & 17.801 & 19.303 \\
\hline
\end{tabular}

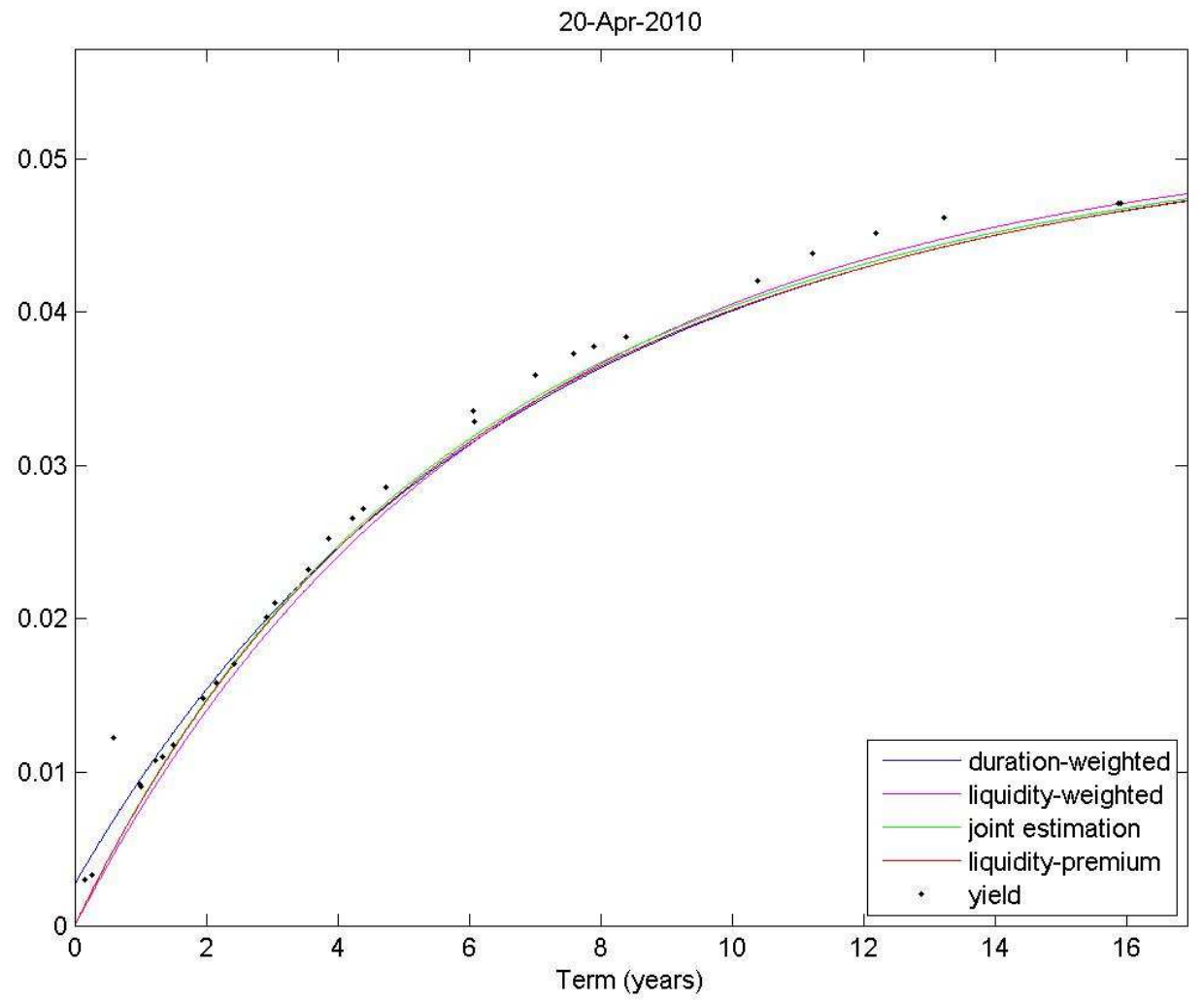


TABLE $3 b$

\begin{tabular}{|lrrrr|}
\hline & & $\mathbf{1 1 / 0 5 / 2 0 1 0}$ & & \\
& $\begin{array}{c}\text { Duration- } \\
\text { Liquidity- } \\
\text { Weighted }\end{array}$ & $\begin{array}{l}\text { Mean-Variance } \\
\text { joint estimation }\end{array}$ & $\begin{array}{c}\text { Liquidity } \\
\text { Premia Model }\end{array}$ \\
$\gamma_{0}$ & - & -15.206 & -0.012 & 0.000 \\
$\gamma_{1}$ & - & 0.013 & 0.000 & -0.043 \\
$\gamma_{2}$ & - & 0.939 & 1.906 & 2.034 \\
$\alpha$ & - & - & - & 0.000599 \\
$\varphi_{1}$ & 0.046 & 0.031 & 0.026 & 0.024 \\
$\varphi_{2}$ & -0.041 & 0.000 & 0.000 & 0.000 \\
$\varphi_{3}$ & -0.002 & 0.000 & 0.000 & 0.000 \\
$\varphi_{4}$ & 0.067 & 0.084 & 0.105 & 0.110 \\
$\varphi_{5}$ & 2.337 & 1.754 & 0.967 & 0.888 \\
$\varphi_{6}$ & 51.435 & 16.800 & 22.228 & 21.716 \\
\hline
\end{tabular}

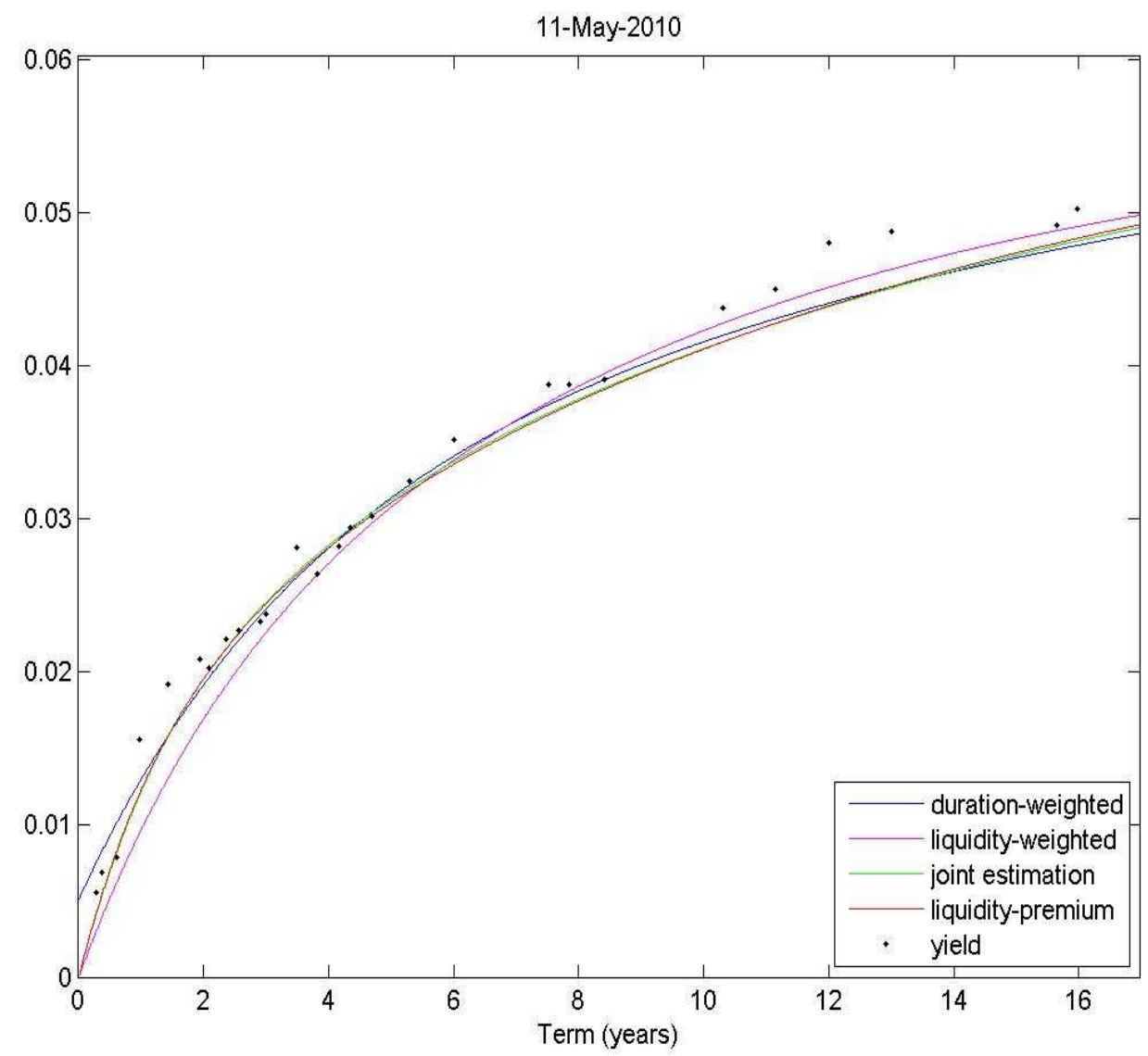


TABLE $3 c$

\begin{tabular}{|lrrrr|}
\hline \multicolumn{5}{c}{$\mathbf{0 7 / 0 7 / 2 0 1 0}$} \\
& $\begin{array}{r}\text { Duration- } \\
\text { Weighted }\end{array}$ & $\begin{array}{r}\text { Liquidity- } \\
\text { Weighted }\end{array}$ & $\begin{array}{c}\text { Mean-Variance } \\
\text { Joint Estimation }\end{array}$ & $\begin{array}{c}\text { Liquidity } \\
\text { Premia Model }\end{array}$ \\
$\gamma_{0}$ & - & -10.860 & -0.812 & 0.000 \\
$\gamma_{1}$ & - & -0.191 & -0.082 & -0.122 \\
$\gamma_{2}$ & - & -0.200 & 0.810 & 0.803 \\
$\alpha$ & - & - & - & 0.000000 \\
$\varphi_{1}$ & 0.036 & 0.037 & 0.031 & 0.029 \\
$\varphi_{2}$ & -0.032 & 0.000 & 0.000 & 0.000 \\
$\varphi_{3}$ & 0.002 & 0.014 & 0.001 & 0.003 \\
$\varphi_{4}$ & 0.086 & 0.075 & 0.094 & 0.101 \\
$\varphi_{5}$ & 0.729 & 1.198 & 0.416 & 0.374 \\
$\varphi_{6}$ & 23.446 & 17.148 & 17.243 & 16.115 \\
\hline
\end{tabular}

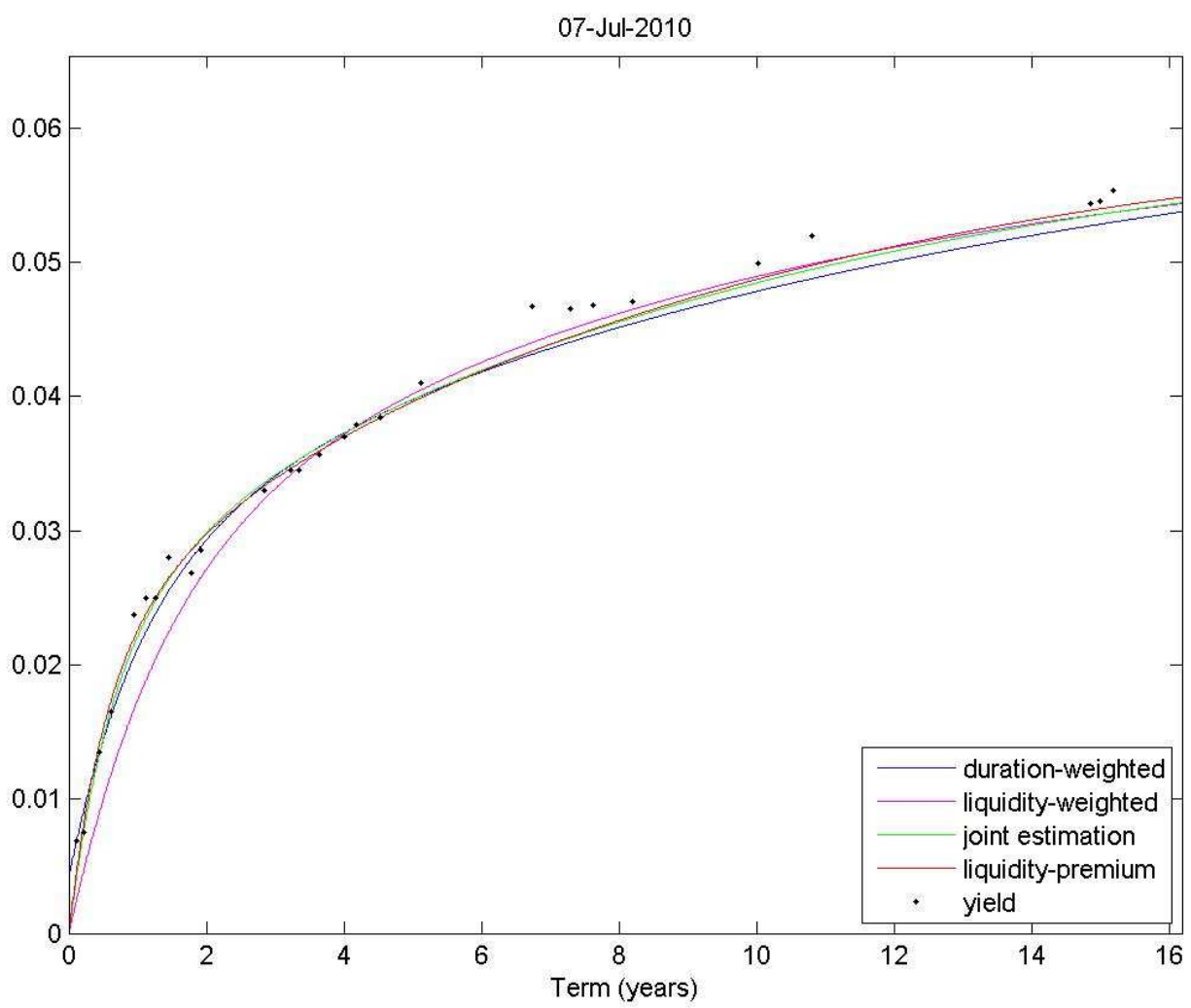

